\title{
Nightlife in the city: drivers of the occurrence and vocal activity of a tropical owl
}

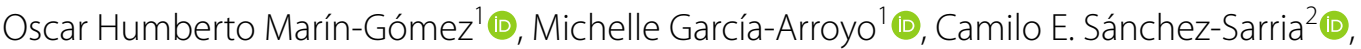 \\ J. Roberto Sosa-López ${ }^{3,4}$ (D) Diego Santiago-Alarcon ${ }^{5}$ (D) and lan MacGregor-Fors ${ }^{1 *}$ (D)
}

\begin{abstract}
Background: Cities differ from non-urban environments by the intensity, scale, and extent of anthropogenic pressures, which can drive the occurrence, physiology, and behavior of the organisms thriving in these settings. Traits as green cover often predict the occurrence patterns of bird species in urban areas. Yet, anthropogenic noise and artificial light at night (ALAN) could also limit the presence and disrupt the behavior of birds. However, there is still a dearth of knowledge about the influence of urbanization through noise and light pollution on nocturnal bird species ecology. In this study, we assessed the role of green cover, noise, and light pollution on the occurrence and vocal activity of the Mottled Owl (Ciccaba virgata) in the city of Xalapa (Mexico).

Methods: We obtained soundscape recordings in 61 independent sites scattered across the city of Xalapa using autonomous recording units. We performed a semi-automated acoustic analysis of the recordings, corroborating all Mottled Owl vocalizations. We calculated two measures of anthropogenic noise at each study site: daily noise (during $24 \mathrm{~h}$ ) and masking noise (mean noise amplitude at night per site that could mask the owl's vocalizations). We further performed generalized linear models to relate green cover, ALAN, daily noise, and masking noise in relation to the owl's occurrence (i.e., detected, undetected). We also ran linear models to assess relationships among the beginning and ending of vocal activity with ALAN, and with the anthropogenic and masking noise levels at the moment of which vocalizations were emitted. Finally, we explored variations of the vocal activity of the Mottled Owl measured as vocalization rate across time.
\end{abstract}

Results: The presence of Mottled Owls increased with the size of green cover and decreased with increases in both artificial light at night and noise levels. At the temporal scale, green cover was positively related with the ending of the owl's vocal activity, while daily noise and ALAN levels were not related to the timing and vocal output (i.e., number of vocalizations). Furthermore, the Mottled Owl showed a marked peak of vocal activity before dawn than after dusk. Although anthropogenic noise levels varied significantly across the assessed time, we did not find an association between high vocal output during time periods with lower noise levels.

Conclusions: Spatially, green cover area was positively related with the presence of the Mottled Owl in Xalapa, while high noise and light pollution were related to its absence. At a temporal scale, daily noise and ALAN levels were not related with the timing and vocal output. This suggests that instead of environmental factors, behavioral contexts such as territoriality and mate interactions could drive the vocal activity of the Mottled Owl. Further studies need to

\footnotetext{
*Correspondence: ian.macgregor@inecol.mx; macgregor.ian@gmail.com

${ }^{1}$ Red de Ambiente y Sustentabilidad, Instituto de Ecología A.C., Carretera antigua a Coatepec 351, El Haya, 91073 Xalapa, Veracruz, Mexico

Full list of author information is available at the end of the article
}

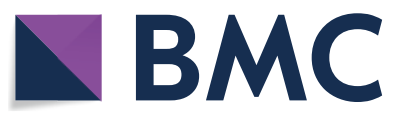

(c) The Author(s) 2020. This article is licensed under a Creative Commons Attribution 4.0 International License, which permits use, sharing, adaptation, distribution and reproduction in any medium or format, as long as you give appropriate credit to the original author(s) and the source, provide a link to the Creative Commons licence, and indicate if changes were made. The images or other third party material in this article are included in the article's Creative Commons licence, unless indicated otherwise in a credit line to the material. If material is not included in the article's Creative Commons licence and your intended use is not permitted by statutory regulation or exceeds the permitted use, you will need to obtain permission directly from the copyright holder. To view a copy of this licence, visit http://creativeco mmons.org/licenses/by/4.0/. The Creative Commons Public Domain Dedication waiver (http://creativecommons.org/publicdomain/ zero/1.0/) applies to the data made available in this article, unless otherwise stated in a credit line to the data. 
incorporate a wider seasonal scale in order to explore the variation of different vocalizations of this species in relation to environmental and biological factors.

Keywords: Anthropogenic noise, Acoustic monitoring, Nighttime ecology, Urban ecology, Urbanization, Vocal activity

\section{Background}

Although cities represent a small portion of the Earth's surface ( 3\% by 2010; Liu et al. 2014), their maintenance, as well as their sprawl and processes have been linked to some of the main global environmental change components (i.e., land-use change, biological invasions, climate change, alteration of biogeochemical cycles; Grimm et al. 2008; Seto et al. 2011; Maxwell et al. 2016). As a result, urbanization has been recurrently linked to the loss and endangerment of biodiversity (Aronson et al. 2014; Maxwell et al. 2016). Moreover, cities are one of the most extreme sources of environmental pollution that pose detrimental consequences on the physiology and behavior of animals (Sol et al. 2013; Isaksson et al. 2018). Anthropogenic noise and artificial light at night (ALAN) are two of the most studied factors of urban pollution that can drive the structure of wildlife communities and their acoustic communication (Hölker et al. 2010; Patón et al. 2012; Gaston et al. 2013; Luther and Gentry 2013; Manzanares Mena and Macías Garcia 2018; MarínGómez et al. 2020).

In comparison to diurnal species, the ecological response of nocturnal birds to urbanization has not been well studied because of their low density and detectability (Weaving et al. 2011; Isaac et al. 2013; Fröhlich and Ciach 2019). Among nocturnal birds, owls are particularly interesting given their role as top predators in most terrestrial habitats, with their presence often being related to ecosystem quality (Isaac et al. 2013; Fröhlich and Ciach 2019). Actually, in some urban areas owls have been identified as important biological control agents of rodent pests (Saufi et al. 2020).

Given the spatial heterogeneity of urban settings and their high density of potential preys for nocturnal raptors (e.g., rodents; Himsworth et al. 2014), these areas can positively influence their abundance (Chace and Walsh 2006; Poppleton 2016). Although some owl species can be negatively affected by urbanization due to potential hazards such as vehicular and window collisions, built structures, artificial lighting, roads, diseases and poisoning (Poppleton 2016; Santiago-Alarcon and Delgado-VC 2017; Serieys et al. 2019; Saufi et al. 2020), other species have shown to thrive in urbanized areas (Gryz and Krauze-Gryz 2019). The ability of owls to deal with urban environments has been shown to depend on the availability of habitats for nesting and foraging to maintain its home range requirements (Galeotti 1990; Fischer et al. 2015; Mori and Bertolino 2015; Poppleton 2016; Kettel et al. 2018). Yet, there is an important dearth of knowledge related to the occupancy and ecology of owls in tropical cities (e.g., Rebolo-Ifrán et al. 2017).

Recent studies on nocturnal birds suggest that anthropogenic noise can have little impact on their habitat occupation (Shonfield and Bayne 2017), while others have shown negative impacts on their foraging efficiency (Mason et al. 2016; Senzaki et al. 2016), decreases of habitat occupation (Fröhlich and Ciach 2017, 2018), and reduction of their species richness in urban settings (Fröhlich and Ciach 2019). Albeit several species can take advantage of ALAN (e.g., diurnal raptors and waders that can increase their foraging efficiency in light polluted sites; Debrot 2014), it is unclear how ALAN may shape the distribution of nocturnal raptors, as well as its influence on nighttime vocal activity (Gorenzel and Salmon 1995; Longcore and Rich 2004; Canário et al. 2012; Gaston and Bennie 2014; Scobie et al. 2016).

Typically, the vocal activity of owls consists of two peaks, one at dusk and another one at dawn (Hardouin et al. 2008; Penteriani and Delgado 2009; Penteriani et al. 2014; Ševčík et al. 2019). Particularly, timing (i.e., starting and ending of vocal activity) and output (i.e., number of vocalizations) are the most important descriptors of the vocal activity of owls (i.e., variation of the vocal output through the day), as well as their behavioral context (Odom and Mennill 2010; Penteriani et al. 2014). For instance, for the Eagle Owl (Bubo bubo), the dusk chorus is related to multiple factors as the time of sunset, the density of conspecifics, and territory quality (Penteriani et al. 2014). However, nighttime vocal activity patterns of owls in urban settings remain largely understudied.

In this study we assessed the relative role of green cover, noise pollution, and ALAN on the occurrence and vocal activity of the Mottled Owl (Ciccaba virgata) in a small-to-medium-sized Neotropical city (Xalapa, Mexico). For this, we used automatic recording units (ARUs) to record the vocalizations of the Mottled Owl in sampling sites located across an urban intensity gradient that ranged from peri-urban forests to heavily urbanized intra-urban areas. Our main goals were to: (1) identify potential relationships between green cover, anthropogenic noise levels, and ALAN with the occurrence of the Mottled Owl; (2) assess relationships between green 
cover, noise levels, and ALAN with the beginning and ending of vocal activity of the Mottled Owl; (3) describe the variation of the vocal output of the Mottled Owl; and (4) explore associations between hourly vocal output and noise levels.

We expected to find a positive association between green cover percentage with the presence of the Mottled Owl given the dependence of this species on well-preserved forested areas for breeding and foraging (Gerhardt et al. 1994; Menq and Anjos 2015; Holt et al. 2019), as well as previous evidence suggesting strong relationships between the quantity of greenspaces with raptors occurrence in urban areas (Dykstra et al. 2012; Poppleton 2016). Furthermore, given the pollution status that noise and ALAN represent, we predicted these variables to be negatively related with the occurrence of the Mottled Owl, as they could limit the habitat use of some owl species (Patón et al. 2012; Scobie et al. 2016; Fröhlich and Ciach 2017, 2019; Shonfield and Bayne 2017). We also predicted that the vocal activity of the Mottled Owl would begin earlier in areas with low anthropogenic noise and light pollution levels, based on previous findings suggesting that both sources of pollution can influence the timing of the singing activity of urban diurnal birds (Dominoni et al. 2016; Marín-Gómez and MacGregorFors 2019). Moreover, given that the Mottled Owl is a forest dependent species (Gerhardt et al. 1994; Holt et al. 2019), we expected to have more records in wellvegetated areas. Finally, for our fourth goal, we predicted higher vocal output of the Mottled Owl to occur during the time periods with less anthropogenic noise, based on recent evidence showing that urban birds respond to traffic noise by adjusting the timing of song output to avoid masking with anthropogenic noise levels (e.g., Dominoni et al. 2016; Sierro et al. 2017).

\section{Methods}

\section{Study area}

We performed this study in Xalapa (Mexico), a smallto-medium-sized city $\left(\sim 64 \mathrm{~km}^{2}\right)$ with a population of $\sim 500,000$ (INEGI 2009). The city comprises an important intra-urban green cover ( $\sim 0 \%$, Falfán et al. 2018$)$ distributed across an elevation gradient ranging between 1100 and $1600 \mathrm{~m}$ a.s.l. (19 32'37"N, 96 54'37"W). Currently, the urban vegetation cover of Xalapa has a mixed flora composed by native and exotic species distributed in private gardens, public parks, natural protected parks, street trees, and peri-urban forest patches (Williams-Linera 1993; Falfán and MacGregor-Fors 2016).

\section{Focal species}

The Mottled Owl (Ciccaba virgata) is considered the most common and widespread forest owl in the
Neotropics, ranging from southern Mexico to Argentina and Brazil (Gerhardt et al. 1994; Enríquez 2015; Holt et al. 2019). This species inhabits a wide variety of habitats from sea level to $2500 \mathrm{~m}$ a.s.l. (e.g., mature forests, second growth forests, coffee and cacao plantations, areas with scattered trees near to small urban settings; Holt et al. 2019). Mottled Owls are cavity nesters associated to forests with high canopy and high abundance of large trees (Gerhardt et al. 1994; Rivera-Rivera et al. 2012; Menq and Anjos 2015; Restrepo-Cardona et al. 2015). This owl is exclusively nocturnal and very territorial (adults could maintain the same territory-home range 20.8 ha-for multiple seasons; Gerhardt et al. 1994; Holt et al. 2019). Regarding its diet, it consumes small to medium size vertebrates (e.g., birds, rats, reptiles, snakes, amphibians), as well as large insects (e.g., beetles, cockroaches, and grasshoppers; Gerhardt et al. 1994; Enríquez 2015). Mottled Owls are considered one of the most vocal nocturnal birds in the Neotropics, showing activity peaks in dawn and dusk (Gerhardt et al. 1994). Although there are no studies focused on its vocal repertoire, five call types predominate along its distribution: (1) common territorial call consisting of a series of 3-10 deep short "hoots", often accelerating and increasing in both pitch and volume (wo-oh', wo-oh', wo-oH', wo-oH', wo-oh') before fading, (2) single resonant hoots (whowh', wh-owh'), (3) a series of 1-3 grunts alone, emitted by both sexes, (4) a cat-like call used by females to solicit food, and (5) duets, consisting of fairly soft series of resonant hoots (Howell and Webb 1995; Holt et al. 2019).

\section{Sampling design}

To record the vocal activity of the Mottled Owl across Xalapa, we used 22 autonomous recording units (hereinafter referred to as ARUs; 16 SM4 and 6 SM3 Song Meters; Wildlife Acoustics Inc. (), Maynard, MA) placed at 61 independent sampling sites (see Acoustic recordings for further methodological details). Our sampling design considered different ecological conditions of the urbanization intensity gradient of the city, ranging from heavily urbanized intra-urban areas (e.g., residential and commercial areas, gardens, parks, and greenspaces) to lowly urbanized areas (e.g., peri-urban forests; Fig. 1). Sampling sites were selected based on their representativeness across the urbanization intensity gradient of Xalapa, as well as security conditions and permission from house owners and municipality authorities to set our acoustic equipment in their properties. Thus, these sites represent different ecological conditions of the urban intensity gradient of the city, defined by the percentage of green cover within a $50 \mathrm{~m}$ radius buffer for each sampling site based on the satellite image classification from a previous study (Falfán et al. 2018). To ensure the independence of 

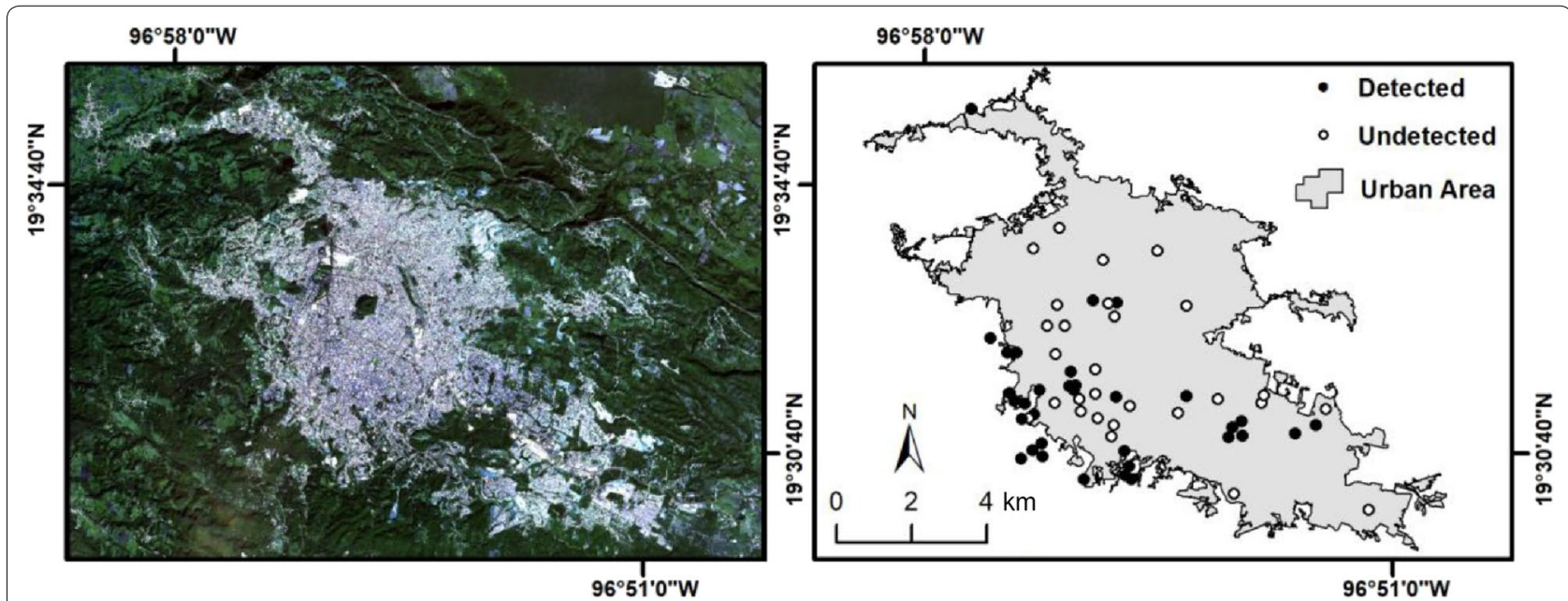

Fig. 1 Map of the study area showing the landscape of the Xalapa city (left), and the distribution of sampling points indicating the occurrence of the Mottled Owl (Ciccaba virgata) (right)

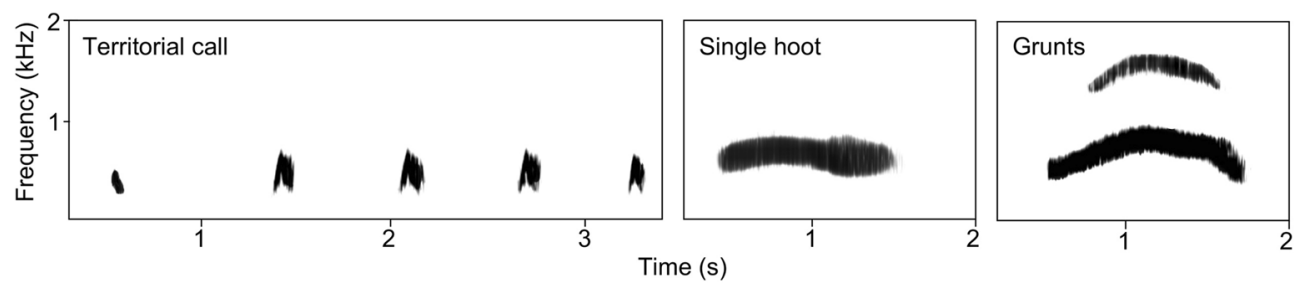

Fig. 2 Spectrogram of the most frequent vocalizations of the Mottled Owl (Ciccaba virgata) in the study area

sampling sites, we located them at a minimum distance of $300 \mathrm{~m}$ (following Ralph et al. 1996). We placed ARUs in rooftops, balconies, or gardens between 3 and $12 \mathrm{~m}$ above ground $(6.4 \pm \mathrm{SD} 3.0 \mathrm{~m})$ attached to trees or poles using a cable lock.

\section{Acoustic recordings}

We recorded the soundscape at each of the 61 sampling sites for three consecutive days from 03 June 2017 to 18 June 2017, corresponding with the breeding season. It is notable that each ARU had two omnidirectional microphones allowing recording sounds with an equal gain from all directions around it. As recommended by Shonfield et al. (2018), we recorded in stereo format to have a backup channel in case that one of the microphones failed. Each ARU was tested in laboratory prior to fieldwork in order to assure the same parameter settings. We kept the same gain settings of the left and right channel microphones of ARUs (SM4: + 42.2 dB; SM3:+24 dB). We programmed each ARU to obtain a continuous long recording during the main vocal activity peaks: the dawn chorus (135 min before and after sunrise) and the dusk chorus (135 min before and after sunset). During the remaining time periods (i.e., day, night) we programmed a schedule to record for $5 \mathrm{~min}$ every $15 \mathrm{~min}$ (i.e., $5 \mathrm{~min}$ on, 10 min off). All recordings were stored in SD cards at a sampling rate of $48,000 \mathrm{~Hz}$ and 16 bits.

\section{Acoustic analysis}

We first used Kaleidoscope Pro (version 5.2; Wildlife Acoustics Inc., Concord, MA, USA) to build an automatic recognizer for Mottled Owl vocalizations (Additional file 1, Fig. 2). However, given the low rate of true positives and the high noise levels that predominate in the studied urban environment, we considered a semiautomated approach to analyze our data (see Additional file 1). This procedure consisted of running a recognition algorithm followed by a clustering and recognition approach that uses Hidden Markov Models to detect and classify similar vocalizations (Wildlife Acoustics 2019). Afterwards, the program generated an output file of the results that can be used to add manual annotations of the ID of each acoustic signal (i.e., manual validation). To construct the semi-automated recognizer, we exclusively 
considered the first day of recordings $(660 \mathrm{~h})$ and ran a cluster analysis in Kaleidoscope Pro according to the following signal parameters: $250-12,000 \mathrm{~Hz}, 0.1-7.5 \mathrm{~s}$ duration and $0.35 \mathrm{~s}$ as the maximum inter-syllable gap (cluster analysis parameters were left as default). We then manually reviewed the resulting acoustic detections in the output file by checking one single channel in order to identify each vocalization of the Mottled Owl based on the visual shape of their acoustic features on the spectrograms (Fig. 2). We used Mottled Owl vocalizations as evidence of their presence in our study sites.

Additionally, we used a manual approach to check the remaining recordings of the second and third day. For this, we used Kaleidoscope viewer to check the spectrogram to record the detections of the Mottled Owl at each site by using the arrow cursors to quickly advance through the recordings within each folder (i.e., corresponding to recordings for each sampling site). Finally, the occurrence of the Mottled Owl was classified as detected if the species was recorded at least once in our sample.

To describe the daily vocal activity of the Mottled Owl, we counted the number of vocalizations emitted per hour at each sampling site using the first day of recordings. Regarding vocal timing, we used the first day of recordings to calculate the beginning (relative to sunset) and ending (relative to sunrise) of vocal activity of the Mottled Owl. We retrieved sunrise/sunset data from the US Naval Observatory (http://aa.usno.navy.mil). Negative values represent vocalizing times before sunset or sunrise, while positive values represent vocalizing times after sunset or sunrise.

\section{Site variable measurements}

To obtain the percentage of green cover around each sampling recording site, we used the satellite image classification of a previous study of Xalapa (Falfán et al. 2018) within a $50 \mathrm{~m}$ radius buffer from the centroid (i.e., geometric center of a shape) of each sampling site. For ALAN measurements, we recorded the lux levels emitted by street lights and other urban-related sources at five different locations within each surveyed site considering a $50 \mathrm{~m}$ radius area, one at the site's centroid and one at each outermost cardinal point $(n=5)$. For this, we used a BK Precision 615 digital light meter mounted on a tripod $1.5 \mathrm{~m}$ above ground level pointing to the sky to record average lux values for $1 \mathrm{~min}$ at 22:00 $\mathrm{h}$.

We extracted noise levels from the soundscape recordings obtained from ARUs using Kaleidoscope Pro. This software provides a range of weighted 1/3-octave band frequency levels bands that can be used to generate specific analysis. These octave bands are useful in environmental noise measurements due to the quantification of power in frequency bands expressed on a logarithmic scale (Merchant et al. 2015). We ran the noise analyses using the overall dataset (2013 $\mathrm{h}$ of recordings) and then calculated the mean amplitude for a sample period of 1 min every minute for each recording day per site. In total, we obtained 655 noise measurements per day for each sampled site, 179 of which corresponded to nighttime.

We considered two complementary measures of noise: daily noise and masking noise. We defined daily noise as the mean noise amplitude per day $(24 \mathrm{~h})$ at each study site considering the 1/3-octave band levels from $19.7 \mathrm{~Hz}$ to $2000.0 \mathrm{~Hz}$, which represents the frequency bands where anthropogenic noise is concentrated (Luther and Gentry 2013; Slabbekoorn 2013). We defined masking noise as the mean noise amplitude at night per site that could mask the vocalizations of the Mottled Owl (Fig. 2), considering 1/3-octave band levels from 250 to $1000 \mathrm{~Hz}$. Given that noise levels are based on a logarithmic scale, which means that decibels increase exponentially, we calculated the average of such logarithmic noise values. As we did not calibrate the microphones and recorders before being placed in the field, we expressed noise levels as a relative measure ( $\mathrm{dB}$ relative to 1 Volt). Thus, noisier sites are characterized by having values near to $0 \mathrm{~dB}$ while quieter sites present values near to $-100 \mathrm{~dB}$.

\section{Statistical analysis}

To evaluate potential associations between green cover, ALAN, daily noise, and masking noise in relation with the occurrence (i.e., detected, undetected) of the Mottled Owl in Xalapa, we used generalized linear models (GLMs) with a binomial distribution (link=logit). Given that both noise variables analyzed in this study are tightly correlated $(r=0.92, p<0.001)$ but could have different ecological meanings, we ran two independent GLMs in order to test the potential relationships between them and the occurrence of the Mottled Owl.

We used two additional linear models (LMs) to test relationships among the beginning and ending of vocal activity with ALAN, and with the anthropogenic and masking noise levels at the moment of which vocalizations were emitted. Given the absence of interactions between the independent variables in the models, we only present the results of LMs without considering interaction effects.

Before assessing relationships between vocal output and noise levels, we tested the variations of both daily and masking noise levels during nighttime. For this, we obtained the values of daily and masking noise levels calculated in samples of $1 \mathrm{~min}$ per site for the first recording day (as described above). After obtaining the logarithmic 
mean for both noise variables per hour, we used heat maps (graphical representation of data where values are represented with gradually changing colors) to visualize variations on noise levels across sampling sites and time period (hours). To test whether daily and masking noise levels varied across sampling sites and time we ran two separately LMs considering noise levels as depended variables (daily, masking), while sampling site and hour were the independent variables. We also assessed daytime and nighttime differences on daily noise with a Welch $t$ test. Finally, we performed a Pearson correlation to test the association between green cover with noise levels.

To explore relative variations on the vocal activity of the Mottled Owl, we counted the total number of vocalizations recorded per hour (i.e., vocalization rate) at each sampling site from 18:00-19:00 to 06:00-07:00 $\mathrm{h}$ and then plotted the cumulative number of vocalizations per hour and the variation of vocal output per hour across sampling sites. We also used a non-parametric Spearman's rank correlation to assess potential relationships between vocal activity with daily and masking noise levels. We used a non-parametric approach in this case because our data did not comply with the parametric assumptions.

All statistical analyses were run in R ( $\mathrm{R}$ Core Team 2018). Before fitting the models, we carried out exploratory analysis to assess outliers in the data, variance homogeneity, and normality of dependent variables, as well as multicollinearity among independent variables (Zuur et al. 2010). Furthermore, all models were validated through residual diagnostic plots (Crawley 2012).

\section{Results}

We detected Mottled Owls in 33 of the 61 sampling sites across the city of Xalapa (Fig. 1, Table 1). Results of the GLMs showed that the presence of Mottled Owls in the city was positively related to areas with high green cover ( $70 \pm \mathrm{SD} 33 \%$; Table 2), whereas its presence was negatively related with ALAN $(1.11 \pm$ SD $1.89 \mathrm{~lx}$ ) and daily noise levels (daily noise $=-75.6 \pm \mathrm{SD}$ 13.4 dB; masking noise $=-82.2 \pm$ SD 12.4 dB; Table 2, Fig. 3).

The beginning of the vocal activity of the Mottled Owl varied from $40 \mathrm{~min}$ before sunset to $76 \mathrm{~min}$ after sunset $(21.6 \pm$ SD $30.9 \mathrm{~min})$, with the ending of vocal activity varying from $91 \mathrm{~min}$ before sunrise to $1 \mathrm{~min}$ after sunrise $(-45.5 \pm \mathrm{SD} 23.2 \mathrm{~min})$. The beginning of the vocal activity was not related with green cover, ALAN, or noise levels, although the beginning of vocal activity did show a non-significant tendency to start earlier in sites exposed to higher masking noise levels (Table 3). However, the ending of the vocal activity was positively related with green cover, but not with ALAN, nor noise levels (Table 3).
Daily and masking noise levels varied significantly across sampling sites and time periods (daily noise: $F_{50,621}=188.6, \quad p<0.001, \quad r^{2}=0.93 ;$ masking noise: $F_{38,297}=74.54, p<0.001, r^{2}=0.89$; Fig. 4$)$. Among sampling sites, those with higher green cover had lower noise levels $(r=-0.48, n=670, p<0.001$; Fig. 4). Daily noise levels were significantly lower at night $(-84.7 \pm 12.0 \mathrm{~dB})$ when compared to those at day time $(-79.0 \pm 11.7 \mathrm{~dB})$ across sites (Welch $t$ test: $t=6.23, \mathrm{df}=610, p<0.001$; Fig. 4). Furthermore, both daily and masking noise levels varied across nighttime (Fig. 4). Noise levels retrieved in both assessed variables were higher between 19:00 to 22:00 h (daily noise: $-80.7 \pm 12.8 \mathrm{~dB}$; masking noise: $-86.8 \pm 13.6 \mathrm{~dB}$ ), decreasing at midnight, to reach lower values between 02:00 to $04: 00 \mathrm{~h}$ (daily noise: $-88.0 \pm 11.3 \mathrm{~dB}$; masking noise: $-92.1 \pm 11.7 \mathrm{~dB}$ ), and then increasing again between $05: 00$ to $06: 00$ (daily noise: $-89.5 \pm 10.7 \mathrm{~dB}$ ).

Overall, Mottled Owls in the study area showed three peaks of vocal activity: sunset, midnight and one intense peak during the transition between night and sunrise (Fig. 5), in which the highest peaks occurred at 22:00 $\mathrm{h}, 01: 00 \mathrm{~h}$ and 04:00 to 06:00 $\mathrm{h}$, while vocal rate remained lower through late night and dusk (Fig. 6). Moreover, vocal rate was not related to daily noise $\left(r_{\mathrm{s}}=0.03, p=0.74, n=103\right.$; Fig. 6) nor masking noise levels $\left(r_{\mathrm{s}}=-0.06, p=0.48, n=103\right.$; Fig. 6).

\section{Discussion}

Understanding how wildlife responds to multiple pressures imposed by urbanization is an important task to provide crucial information about its ecological requirements and conservation actions (Isaksson et al. 2018). Here we provide the first assessment of the role of green cover, noise, and light pollution on the occurrence and vocal activity of a tropical owl. As expected, we found a positive association between green cover and the presence of the Mottled Owl, as well as a negative relationship between ALAN and noise levels with its occurrence in the city of Xalapa. Results of this study indicate that this owl is well represented along the intra-urban areas of the city, especially those with $>25 \%$ of green cover; yet, high levels of noise and light pollution seem to limit its presence. Contrary to our predictions, the beginning and the ending of vocal activity were not related to daily noise nor light pollution levels, suggesting that both ALAN and daily noise levels did not influence the timing of the vocal activity. Regarding its vocal activity, the Mottled Owl showed a marked peak of vocal output before dawn. However, despite both daily and masking noise levels varied significantly across the surveyed time, we did not find 
Table 1 Location of automatic recording units (ARUs), Mottled Owl occurrence, green cover, and pollution variables in Xalapa

\begin{tabular}{|c|c|c|c|c|c|c|}
\hline Latitude (N) & Longitude (W) & $\begin{array}{l}\text { Mottled Owl } \\
\text { detection }^{\mathrm{a}}\end{array}$ & $\begin{array}{l}\text { Green cover } \\
(\%)\end{array}$ & ALAN (lux) & Daily noise (dB) & Masking noise (dB) \\
\hline $19^{\circ} 31^{\prime} 33^{\prime \prime}$ & $97^{\circ} 4^{\prime} 50^{\prime \prime}$ & - & 15 & 6.4 & -47.22 & -59.72 \\
\hline $19^{\circ} 35^{\prime} 43^{\prime \prime}$ & $97^{\circ} 4^{\prime} 42^{\prime \prime}$ & - & 68 & 2 & -89.97 & -85.92 \\
\hline $19^{\circ} 31^{\prime} 36^{\prime \prime}$ & $97^{\circ} 4^{\prime} 32^{\prime \prime}$ & & 36 & 0.6 & -52.96 & -83.19 \\
\hline $19^{\circ} 31^{\prime 3} 33^{\prime \prime}$ & $97^{\circ} 7^{\prime} 5^{\prime \prime}$ & & 95 & 0.7 & -79.9 & -76.57 \\
\hline $19^{\circ} 31^{\prime} 21^{\prime \prime}$ & $97^{\circ} 4^{\prime} 18^{\prime \prime}$ & & 54 & 6.1 & -43.53 & -51.57 \\
\hline $19^{\circ} 31^{\prime} 31^{\prime \prime}$ & $97^{\circ} 3^{\prime} 18^{\prime \prime}$ & • & 98 & 0 & -87.06 & -88.19 \\
\hline $19^{\circ} 30^{\prime} 22^{\prime \prime}$ & $97^{\circ} 5^{\prime \prime \prime}$ & · & 100 & 0 & -90.06 & -94.69 \\
\hline $19^{\circ} 31^{\prime} 31^{\prime \prime}$ & $97^{\circ} 5^{\prime \prime \prime}$ & & 15 & 6.9 & -73.11 & -79.97 \\
\hline $19^{\circ} 33^{\prime} 42^{\prime \prime}$ & $97^{\circ} 3^{\prime} 37^{\prime \prime}$ & & 15 & 4.6 & -61.6 & -67.89 \\
\hline $19^{\circ} 32^{\prime} 55^{\prime \prime}$ & $97^{\circ} 4^{\prime} 52^{\prime \prime}$ & . & 100 & 1.3 & -81.69 & -98.76 \\
\hline $19^{\circ} 31^{\prime} 43^{\prime \prime}$ & $97^{\circ} 4^{\prime} 8^{\prime \prime}$ & $\cdot$ & 8 & 0 & -73.16 & -84.31 \\
\hline $19^{\circ} 31^{\prime} 40^{\prime \prime}$ & $97^{\circ} 3^{\prime} 41^{\prime \prime}$ & - & 61 & 0.2 & -77.43 & -76.06 \\
\hline $19^{\circ} 31^{\prime} 28^{\prime \prime}$ & $97^{\circ} 3^{\prime} 55^{\prime \prime}$ & & 4 & 1.5 & -75.52 & -80.35 \\
\hline $19^{\circ} 30^{\prime} 33^{\prime \prime}$ & $97^{\circ} 5^{\prime \prime \prime}$ & - & 99 & 0 & * & * \\
\hline $19^{\circ} 30^{\prime} 56^{\prime \prime}$ & $97^{\circ} 6^{\prime} 32^{\prime \prime}$ & . & 100 & 0 & -82.48 & -84.51 \\
\hline $19^{\circ} 30^{\prime} 25^{\prime \prime}$ & $97^{\circ} 4^{\prime} 58^{\prime \prime}$ & . & 100 & 0 & -93.39 & -98.17 \\
\hline $19^{\circ} 32^{\prime} 25^{\prime \prime}$ & $97^{\circ} 2^{\prime} 57^{\prime \prime}$ & . & 92 & 0.2 & -89.51 & -95.17 \\
\hline $19^{\circ} 31^{\prime} 25^{\prime \prime}$ & $97^{\circ} 5^{\prime} 3^{\prime \prime}$ & & 30 & 2.5 & -60.05 & -66.58 \\
\hline $19^{\circ} 31^{\prime} 37^{\prime \prime}$ & $97^{\circ} 3^{\prime} 14^{\prime \prime}$ & $\cdot$ & 37 & 1.1 & -78.01 & -91.29 \\
\hline $19^{\circ} 31^{\prime} 19^{\prime \prime}$ & $97^{\circ} 3^{\prime 3} 36^{\prime \prime}$ & · & 47 & 1.3 & -54.29 & -58.71 \\
\hline $19^{\circ} 30^{\prime} 59^{\prime \prime}$ & $97^{\circ} 4^{\prime} 46^{\prime \prime}$ & & 23 & 4.1 & -46.72 & -60.28 \\
\hline $19^{\circ} 33^{\prime} 60^{\prime \prime}$ & $97^{\circ} 4^{\prime} 1^{\prime \prime}$ & & 90 & 3.6 & -79.97 & -87.42 \\
\hline $19^{\circ} 31^{\prime} 15^{\prime \prime}$ & $97^{\circ} 3^{\prime 2} 24^{\prime \prime}$ & . & 91 & 0 & -62.76 & -68.03 \\
\hline $19^{\circ} 31^{\prime} 15^{\prime \prime}$ & $97^{\circ} 331^{\prime \prime}$ & & 64 & $0 . .5$ & -55.84 & -61.8 \\
\hline $19^{\circ} 31^{\prime \prime 3} 3^{\prime \prime}$ & $97^{\circ} 5^{\prime} 54^{\prime \prime}$ & $\cdot$ & 20 & 6.2 & -71.95 & -86.1 \\
\hline $19^{\circ} 30^{\prime} 59^{\prime \prime}$ & $97^{\circ} 7^{\prime} 33^{\prime \prime}$ & . & 47 & 1 & -81.94 & -87.51 \\
\hline $19^{\circ} 32^{\prime} 56^{\prime \prime}$ & $97^{\circ} 4^{\prime} 30^{\prime \prime}$ & $\cdot$ & 4 & 5.5 & -71.5 & -81.1 \\
\hline $19^{\circ} 32^{\prime} 13^{\prime \prime}$ & $97^{\circ} 3^{\prime 2} 20^{\prime \prime}$ & $\cdot$ & 44 & 0.4 & -70.59 & -79.48 \\
\hline $19^{\circ} 33^{\prime} 31^{\prime \prime}$ & $97^{\circ} 4^{\prime} 40^{\prime \prime}$ & & 30 & 1.6 & -73.31 & -79.42 \\
\hline $19^{\circ} 30^{\prime} 41^{\prime \prime}$ & $97^{\circ} 3^{\prime 2} 24^{\prime \prime}$ & . & 100 & 0 & -86.91 & -89.74 \\
\hline $19^{\circ} 31^{\prime} 36^{\prime \prime}$ & $97^{\circ} 4^{\prime} 32^{\prime \prime}$ & & 39 & 18.6 & -64.14 & -70.46 \\
\hline $19^{\circ} 32^{\prime} 13^{\prime \prime}$ & $97^{\circ} 3^{\prime} 12^{\prime \prime}$ & - & 64 & 0.7 & -85.22 & -88.37 \\
\hline $19^{\circ} 30^{\prime} 46^{\prime \prime}$ & $97^{\circ} 4^{\prime} 58^{\prime \prime}$ & $\cdot$ & 84 & 0 & -79.85 & -82.37 \\
\hline $19^{\circ} 30^{\prime} 8^{\prime \prime}$ & $97^{\circ} 6^{\prime} 36^{\prime \prime}$ & & 3 & 3.1 & -71.28 & -73.63 \\
\hline $19^{\circ} 31^{\prime} 43^{\prime \prime}$ & $97^{\circ} 4^{\prime} 13^{\prime \prime}$ & $\cdot$ & 54 & 5.2 & -53.78 & -61.14 \\
\hline $19^{\circ} 32^{\prime} 42^{\prime \prime}$ & $97^{\circ} 4^{\prime} 50^{\prime \prime}$ & & 52 & 1.4 & -47.85 & -61.26 \\
\hline $19^{\circ} 31^{\prime} 57^{\prime \prime}$ & $97^{\circ} 4^{\prime} 32^{\prime \prime}$ & & 0 & 4.4 & -50.83 & -58.83 \\
\hline $19^{\circ} 31^{\prime} 14^{\prime \prime}$ & $97^{\circ} 4^{\prime} 33^{\prime \prime}$ & & 11 & 4.3 & -68.53 & -81.27 \\
\hline $19^{\circ} 33^{\prime} 39^{\prime \prime}$ & $97^{\circ} 5^{\prime} 29^{\prime \prime}$ & & 0 & 6.9 & -67.99 & -73.09 \\
\hline $19^{\circ} 31^{\prime} 10^{\prime \prime}$ & $97^{\circ} 6^{\prime} 45^{\prime \prime}$ & . & 100 & 0 & -83.64 & -87.85 \\
\hline $19^{\circ} 30^{\prime} 58^{\prime \prime}$ & $97^{\circ} 6^{\prime} 45^{\prime \prime}$ & $\cdot$ & 100 & 0 & -81.84 & -86 \\
\hline $19^{\circ} 31^{\prime} 5^{\prime \prime}$ & $97^{\circ} 6^{\prime} 36^{\prime \prime}$ & - & 100 & 0 & -79.48 & -83.98 \\
\hline $19^{\circ} 31^{\prime} 28^{\prime \prime}$ & $97^{\circ} 3^{\prime 2} 27^{\prime \prime}$ & · & 79 & 0.4 & -58.31 & -62.84 \\
\hline $19^{\circ} 31^{\prime} 9^{\prime \prime}$ & $97^{\circ} 4^{\prime} 48^{\prime \prime}$ & & 73 & 5.9 & -41.58 & -51.4 \\
\hline $19^{\circ} 32^{\prime} 53^{\prime \prime}$ & $97^{\circ} 3^{\prime} 57^{\prime \prime}$ & & 23 & 2.4 & * & $*$ \\
\hline $19^{\circ} 32^{\prime} 51^{\prime \prime}$ & $97^{\circ} 5^{\prime} 55^{\prime \prime}$ & & 6 & 4.3 & -51.25 & -60.63 \\
\hline $19^{\circ} 32^{\prime} 53^{\prime \prime}$ & $97^{\circ} 4^{\prime} 44^{\prime \prime}$ & & 100 & 0 & -83.64 & -94.67 \\
\hline $19^{\circ} 32^{\prime} 35^{\prime \prime}$ & $97^{\circ} 3^{\prime} 48^{\prime \prime}$ & & 10 & 7 & -62.64 & -77.54 \\
\hline
\end{tabular}


Table 1 (continued)

\begin{tabular}{|c|c|c|c|c|c|c|}
\hline Latitude (N) & Longitude (W) & $\begin{array}{l}\text { Mottled Owl } \\
\text { detection }^{\mathrm{a}}\end{array}$ & $\begin{array}{l}\text { Green cover } \\
(\%)\end{array}$ & ALAN (Iux) & Daily noise (dB) & Masking noise (dB) \\
\hline $19^{\circ} 31^{\prime} 20^{\prime \prime}$ & $97^{\circ} 8^{\prime} 1^{\prime \prime}$ & & 17 & 2.5 & -55.68 & -58.88 \\
\hline $19^{\circ} 30^{\prime} 42^{\prime \prime}$ & $97^{\circ} 3^{\prime} 43^{\prime \prime}$ & - & 100 & 0 & -90.9 & -96.37 \\
\hline $19^{\circ} 30^{\prime} 48^{\prime \prime}$ & $97^{\circ} 3^{\prime 3} 33^{\prime \prime}$ & - & 100 & 0 & -89.98 & -96.89 \\
\hline $19^{\circ} 30^{\prime} 54^{\prime \prime}$ & $97^{\circ} 3^{\prime} 42^{\prime \prime}$ & · & 100 & 0 & -86.59 & -95.58 \\
\hline $19^{\circ} 31^{\prime} 6^{\prime \prime}$ & $97^{\circ} 7^{\prime} 52^{\prime \prime}$ & - & 25 & 2.2 & -56.39 & -62.52 \\
\hline $19^{\circ} 32^{\prime} 10^{\prime \prime}$ & $97^{\circ} 3^{\prime} 56^{\prime \prime}$ & & 25 & 5 & -73.02 & -80.49 \\
\hline $19^{\circ} 32^{\prime} 35^{\prime \prime}$ & $97^{\circ} 4^{\prime} 4^{\prime \prime}$ & & 27 & 4.5 & -76.11 & -82.51 \\
\hline $19^{\circ} 29^{\prime} 53^{\prime \prime}$ & $97^{\circ} 89^{\prime \prime}$ & & 25 & 3.1 & -64.83 & -73.2 \\
\hline $19^{\circ} 31^{\prime} 55^{\prime \prime}$ & $97^{\circ} 4^{\prime} 10^{\prime \prime}$ & · & 100 & 0 & -58.19 & -83.78 \\
\hline $19^{\circ} 31^{\prime} 30^{\prime \prime}$ & $97^{\circ} 6^{\prime} 23^{\prime \prime}$ & & 39 & 0.5 & -54.76 & -61.37 \\
\hline $19^{\circ} 30^{\prime} 22^{\prime \prime}$ & $97^{\circ} 4^{\prime} 20^{\prime \prime}$ & · & 35 & 0.8 & -72.37 & -76.05 \\
\hline $19^{\circ} 31^{\prime} 26^{\prime \prime}$ & $97^{\circ} 7^{\prime} 3^{\prime \prime}$ & & 42 & 1 & -51.44 & -53.99 \\
\hline $19^{\circ} 31^{\prime} 40^{\prime \prime}$ & $97^{\circ} 4^{\prime} 12^{\prime \prime}$ & - & 39 & 1.6 & -52.88 & -60.41 \\
\hline
\end{tabular}

a Dots represent sites where the owl was detected

* We were unable to retrieve noise data from these sites

Table 2 Relationships between green cover, ALAN, and both noise variables (daily and masking noise), and the occurrence of the Mottled Owl

\begin{tabular}{lcccr}
\hline Model/Variable & $\begin{array}{l}\text { Deviance } \\
\text { residuals }\end{array}$ & df & $\begin{array}{l}\text { Residual } \\
\text { deviance }\end{array}$ & $p$ \\
\hline $\begin{array}{l}\text { Owl occurrence } \sim \text { green cover }+ \text { daily noise }+ \text { ALAN } \\
r^{2}=0.37\end{array}$ & 15.40 & 57 & 65.98 & $<0.001$ \\
Green cover & 4.31 & 56 & 61.66 & 0.038 \\
Daily noise & 4.84 & 55 & 56.82 & 0.028 \\
ALAN & & & & \\
Owl occurrence $\sim$ green cover + masking noise + ALAN & & \\
$r^{2}=0.38$ & 15.40 & 57 & 65.98 & $<0.001$ \\
Green cover & 4.05 & 56 & 61.92 & 0.044 \\
Masking noise & 4.92 & 55 & 57.00 & 0.026 \\
ALAN & & & &
\end{tabular}

Given that noise variables were highly correlated, we ran two GLMs, one including daily noise per site and another one including the masking noise

an association between high vocal output during time periods with lower daily and masking noise levels. This result shows that the behavioral context (i.e., territoriality and mate attraction) could drive the vocal output instead of noise-light pollution, as suggested by Fröhlich and Ciach (2018).

The positive relationship we found between green cover and the presence of the Mottled Owl agrees with findings for other owls, such as the Powerful Owl (Ninox strenua), Tawny Owl (Strix aluco), Barred Owl (Strix varia), and Great Horned Owl (Bubo virginianus) for which tree cover positively influenced habitat availability (Ranazzi et al. 2000; Isaac et al. 2013; Rullman and Marzluff 2014).
In general, the occupancy and abundance of Neotropical forest owls is associated with habitat structure (i.e., canopy height, presence of arboreal cavities, and fallen trees) and the spatial heterogeneity of the landscape (RiveraRivera et al. 2012; Enríquez 2015; Menq and Anjos 2015). In fact, owls in urban settings have been shown to take advantage of habitat heterogeneity due to the opportunities for nesting and high availability of prey items (Lövy and Riegert 2013; Poppleton 2016). Therefore, the Mottled Owl seems to take advantage of urban spatial heterogeneity and greenspaces of Xalapa, which could supply the ecological requirements for maintaining territories and nesting sites (Gerhardt et al. 1994; Lloyd 2013; Enríquez 2015; Menq and Anjos 2015).

The negative association we found between the Mottled Owl presence and ALAN suggests that light pollution should not be overlooked when assessing spatial distribution of this species, and other nocturnal forestsrelated ones, in the city. This finding is in line with a previous study showing that other owl species, that although not related to forests, avoid locations with high levels of ALAN (Burrowing Owl, Athene cunicularia; Scobie et al. 2016). Albeit the relationship was negative, we did record the owl in several sites with high values of ALAN. This is in agreement with studies showing that light pollution can influence prey abundance and availability (Dice 1945; Clarke 1983; Kotler et al. 1991). Thus, it is not surprising that some owls take advantage of ALAN by increasing prey detectability and capture (Clarke 1983; Gaston et al. 2013). Yet, this is not generalizable, as some owls (Long-eared Owl, Asio otus) have shown decreasing foraging activity with ALAN (Kotler et al. 1991). The 

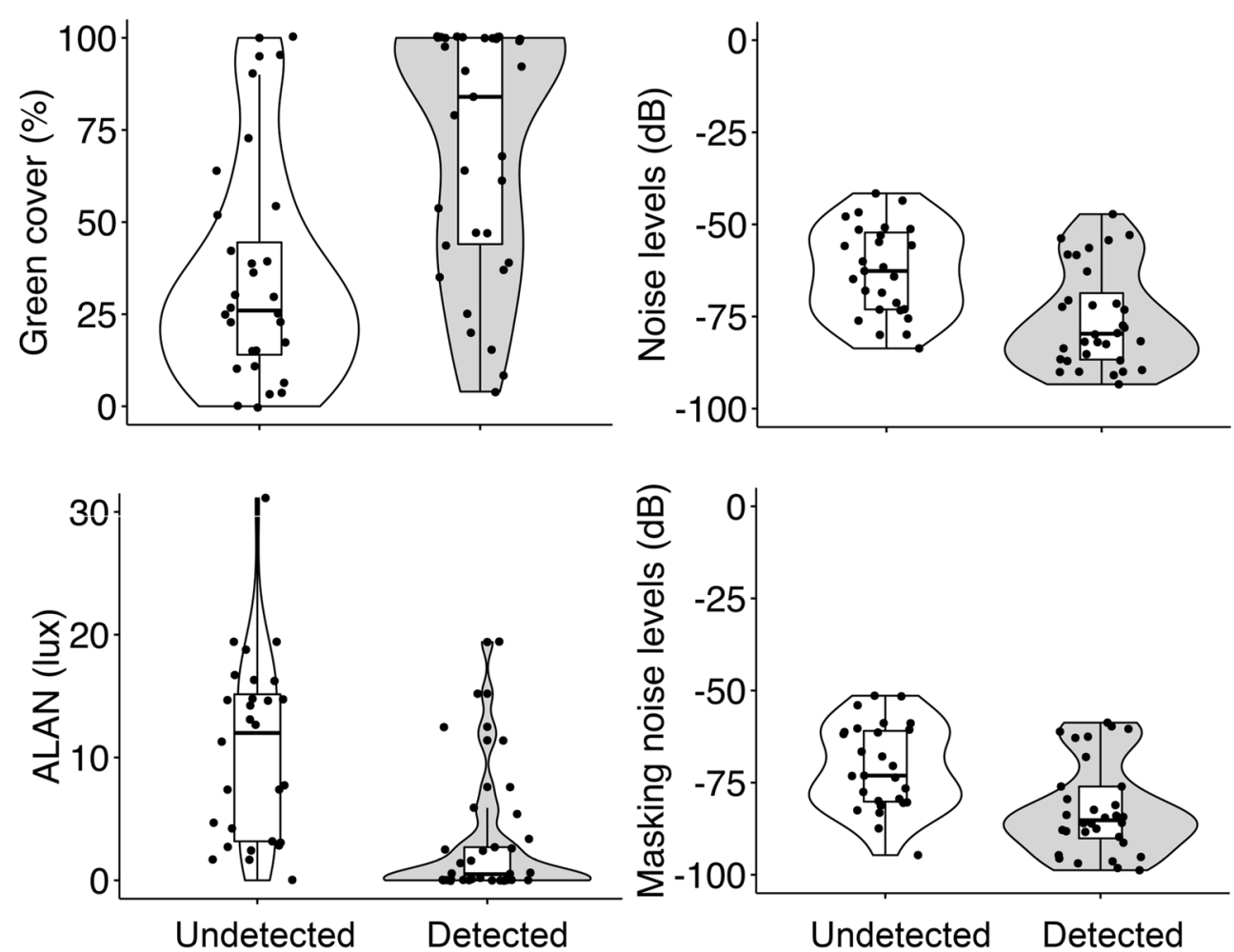

Fig. 3 Associations between green cover, ALAN, daily noise, and masking noise with the occurrence of the Mottled Owl (Ciccaba virgata). Points indicate values for each sampling site; violins represent the cumulative density of points (white $=$ undetected, grey $=$ detected)

Table 3 Results of the linear models testing relationships among the beginning and ending of vocal activity with ALAN, daily noise, and masking noise levels

\begin{tabular}{|c|c|c|c|}
\hline & $F$ & df & $p$ \\
\hline \multicolumn{4}{|c|}{$\begin{array}{l}\text { Beginning } \sim \text { green cover }+A L A N+\text { daily noise } \\
r^{2}=0.15\end{array}$} \\
\hline Green cover (\%) & 0.080 & 1 & 0.784 \\
\hline ALAN (lux) & 0.226 & 1 & 0.646 \\
\hline Daily noise (dB) & 1.160 & 1 & 0.313 \\
\hline \multicolumn{4}{|c|}{$\begin{array}{l}\text { Beginning } \sim \text { green cover }+ \text { ALAN + masking noise } \\
r^{2}=0.35\end{array}$} \\
\hline Green cover (\%) & 0.103 & 1 & 0.756 \\
\hline ALAN (lux) & 0.292 & 1 & 0.603 \\
\hline Masking noise (dB) & 3.825 & 1 & 0.086 \\
\hline \multicolumn{4}{|c|}{$\begin{array}{l}\text { Ending green cover }+ \text { ALAN + daily noise } \\
r^{2}=0.38\end{array}$} \\
\hline Green cover (\%) & 8.941 & 1 & 0.008 \\
\hline ALAN (lux) & 0.487 & 1 & 0.495 \\
\hline Daily noise (dB) & 0.532 & 1 & 0.476 \\
\hline \multicolumn{4}{|c|}{$\begin{array}{l}\text { Ending green cover }+ \text { ALAN }+ \text { masking noise } \\
r^{2}=0.37\end{array}$} \\
\hline Green cover (\%) & 8.778 & 1 & 0.009 \\
\hline ALAN (lux) & 0.478 & 1 & 0.499 \\
\hline Masking noise (dB) & 0.231 & 1 & 0.637 \\
\hline
\end{tabular}

latter could be due to the fact that this species hunts from perches and seems to be attracted to artificial lights (Holt et al. 2019). Thus, in the light of previous knowledge, the presence of Mottled Owls in urban areas with high levels of ALAN (2-6.4 lx) in Xalapa could be related with potential feeding sites. In fact, large insects as rhinoceros beetles and grasshoppers (which are part of the diet of this owl) are attracted to street lamps in Xalapa (MarínGómez, pers. obs.).

Our findings also show that the Mottled Owl tends to be in less noisy sites across the city. These results agree with the growing body of evidence of the negative impacts of noise on habitat occupation and life history of birds in urban settings (Francis et al. 2009; Patón et al. 2012; Luther and Gentry 2013; Slabbekoorn 2013), as well as recent studies suggesting decreases of owl species richness with high nocturnal noise levels (Fröhlich and Ciach 2019). Given that most birds depend on the acoustic channel for communication, anthropogenic noise acts as an environmental filter by limiting species presence according to their tolerance to noise (González-Oreja 2017; Manzanares Mena and Macías Garcia 2018). This is particularly important for forest birds, as the Mottled Owl, which avoids intra-urban areas with higher daily noise levels (i.e., -60 to $-40 \mathrm{~dB}$ ). Although nocturnal noise emissions may reduce hunting efficiency for some 


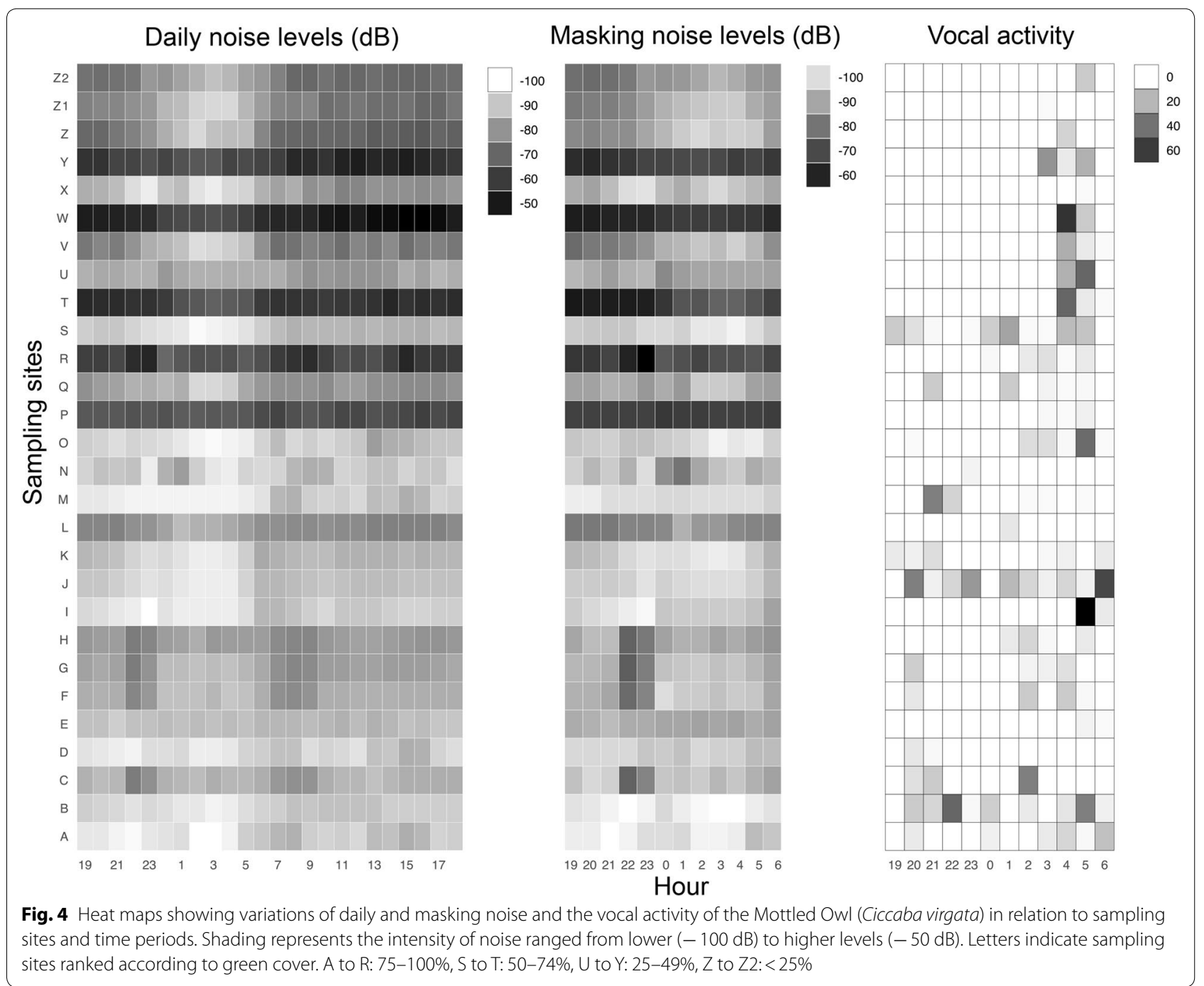

owl species (e.g., Long-eared Owls; Fröhlich and Ciach 2017), evidence also suggests that occurrence of some owl species does not seem to be affected by the presence of industrial noise sources or roads (e.g., Barred Owls, Great Horned Owls, and Boreal Owls Aegolius funereus; Shonfield and Bayne 2017). Therefore, regardless of the predominance of high noise levels in cities, the type and source of noise pollution, as well as the spatial heterogeneity of greenspaces, human settlements could also offer novel feeding resources that owls can exploit in the light of the plethora of implied urban-related hazards and stimuli (Hindmarch and Elliott 2015; Marín-Gómez et al. 2017; Rebolo-Ifrán et al. 2017).

The Mottled Owl showed a marked peak of vocal activity at dawn that was much higher than the one at dusk, which is opposite to what has been documented for Holarctic owls (Hardouin et al. 2008; Penteriani and Delgado 2009; Odom and Mennill 2010; Penteriani et al. 2014).
Although little is known on the behavior of Mottled Owls, it has been documented that this species is a strictly nocturnal bird that becomes active and begins to call at dusk (Holt et al. 2019). Our findings show that the vocal activity of this species did not begin earlier or end later in sites with low noise and light pollution levels suggesting that neither ALAN nor anthropogenic noise drive the timing of the vocal activity of this tropical owl. Although the beginning of vocal activity showed a non-significant tendency to start earlier in sites exposed to higher masking noise levels, overall results are not in line with the growing number of studies showing earlier singing activity and song output for urban birds as a consequence of high levels of anthropogenic noise or ALAN (e.g., Fuller et al. 2007; Da Silva et al. 2015; Sierro et al. 2017).

The positive relationship between green cover and the ending of vocal activity of the Mottled Owls suggests that this species could prolong its vocal activity 


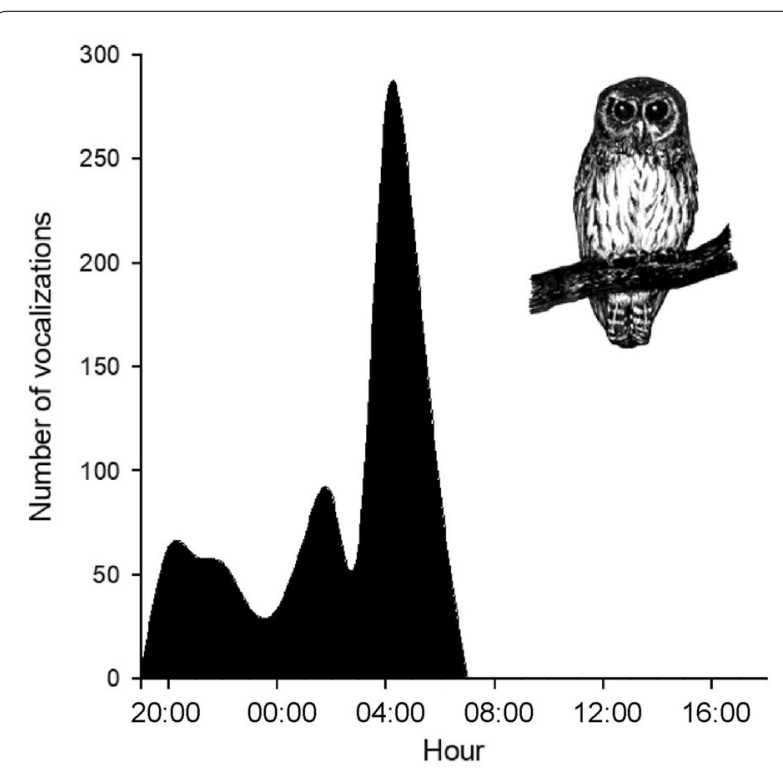

Fig. 5 Cumulative number of vocalizations emitted by the Mottled Owl (Ciccaba virgata) in Xalapa. Illustration by IM-F

until sunrise in sites with a higher green cover (which correspond mostly to peri-urban forests), where population density is expected to be higher than intra-urban greenspaces. Given that the vocal behavior of owls has been associated with population density and interaction among neighbors (Penteriani and Delgado 2009; Penteriani et al. 2014), the vocal activity of this species could be driven by behavioral factors as territorial advertising, mate attraction, duetting interactions between pairs, and time budgets for foraging (Hardouin et al. 2008; Penteriani and Delgado 2009; Odom and Mennill 2010; Penteriani et al. 2014; Holt et al. 2019). Environmental factors such as moonlight and cloud cover can also influence the vocal activity of owls (Mori et al. 2014; Vázquez-Pérez and Enríquez 2016). Hence, future studies should take into account such potential factors affecting the vocal activity of nocturnal urban bird species. One important concern regarding the analytical procedure used in this study is the time spent to manually analyze extensive amounts of information. As suggested in previous studies, the use of automated recognition approach is highly recommended for monitoring owls (Shonfield et al. 2018). However, automated recognition in urban settings poses a great challenge due to high levels of noise and sound types in urban environments (Priyadarshani et al. 2018), as we found for the Mottled Owl. Thus, future algorithms or approaches are needed to improve automated recognition under complex
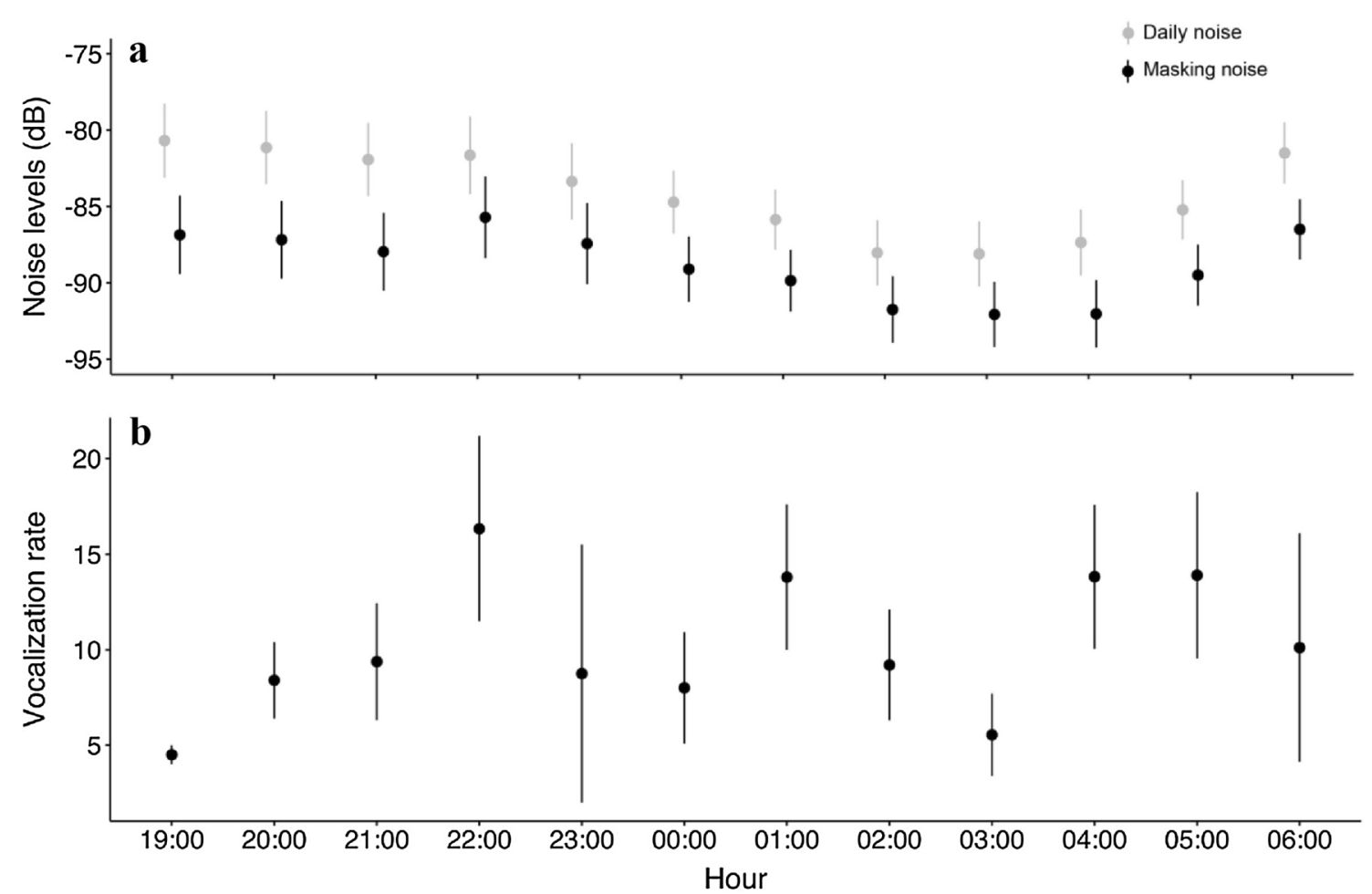

Fig. 6 Variation of daily and masking noise levels per hour (a) and pattern of vocal activity of the Mottled Owl (Ciccaba virgata) measured as vocalization rate (number of vocalizations per hour) (b). Points represent means and the whiskers standard errors 
scenarios similar to those we faced (i.e., Knight et al. 2017).

\section{Conclusions}

Here, we have shown that using passive acoustic sampling is an effective method to assess the occurrence and vocal activity patterns of a tropical owl. Spatially, green cover was positively related to the presence of the Mottled Owl, whereas noise and light pollution were related to its absence in our study sites. Temporally, green cover was positively related to the ending of vocal activity, while anthropogenic noise and ALAN levels were not related with the timing and vocal output, suggesting that instead of environmental factors behavioral traits related with territoriality and mate interactions could drive the vocal activity of the Mottled Owl. These results ought to be interpreted cautiously, considering that the reported patterns correspond to one specific time window. Future studies addressing urban owls could consider including broader seasonal scales to explore the variation of different vocalizations of this species in relation to environmental factors (i.e., noise, ALAN, cloud cover, moonlight and temperature), as well as biological ones (i.e., breeding season, home range size, foraging behavior, mate interaction, duetting).

\section{Supplementary information}

Supplementary information accompanies this paper at https://doi. org/10.1186/s40657-020-00197-7.

Additional file 1. Automated detection of Mottled Owl vocalizations.

\section{Acknowledgements}

We are most thankful to Roberto Berlio, Nelsy Rodríguez, Miguel Ángel Gómez-Martínez, Carlos Trujillo, Juan F. Escobar-Ibáñez, Rafael Rueda-Hernández, Ina Falfán, Pablo Cobos Mejía, and Julian Avila for their assistance in the field. We are also grateful to María del Coro Arizmendi Arriaga, Antonio Celis Murillo, Fernando González García, and Roger Enrique Guevara Hernández for their comments and suggestions to a previous version of this manuscript.

\section{Authors' contributions \\ OHM-G and IM-F conceived the idea. OHM-G, IM-F, JRSL, and DSA designed the study. OHM-G collected the data and conducted the acoustic analyses with assistance of CSS and MGA. OHM-G, IMF, CSS, and MGA performed the statistical analysis. OHM-G led the writing, with all authors contributing sub- stantially. All authors read and approved the final manuscript.}

\section{Funding}

OHM-G and MG-A were supported by the graduate Grant provided by the National Council of Science and Technology (CONACYT 417094 and 416452, respectively), as well as the Doctoral and Master Program of the Instituto de Ecología, A.C. (INECOL, Xalapa). JRSL thanks CONACYT (project Grant 251526) and a chair fellowship at CIIDIR (researcher number 1640; project number 1781) for financial support.

\section{Availability of data and materials}

The data are available from the first author upon request.
Ethics approval and consent to participate

This research complies with the current laws of Mexico, and the research was approved by the Graduated Program of the Instituto de Ecología, A.C. (INECOL, Xalapa).

\section{Consent for publication}

Not applicable.

\section{Competing interests}

The authors declare that they have no competing interests.

\section{Author details}

${ }^{1}$ Red de Ambiente y Sustentabilidad, Instituto de Ecología A.C., Carretera antigua a Coatepec 351, El Haya, 91073 Xalapa, Veracruz, Mexico. ${ }^{2}$ Departamento de Ciencias Naturales y Matemáticas, Pontificia Universidad Javeriana Cali, 760044 Cali, Colombia. ${ }^{3}$ Centro Interdisciplinario de Investigación para el Desarrollo Integral Regional Unidad Oaxaca (CIIDIR), Instituto Politécnico Nacional, Oaxaca, Mexico. ${ }^{4}$ Dirección de Cátedras, Consejo Nacional de Ciencia y Tecnología (CONACYT), Mexico City, Mexico. ${ }^{5}$ Red de Biología y Conservación de Vertebrados, Instituto de Ecología A.C, 91073 Xalapa, Veracruz, Mexico.

Received: 31 December 2019 Accepted: 15 April 2020

Published online: 22 April 2020

\section{References}

Aronson MFJ, La Sorte FA, Nilon CH, Katti M, Goddard MA, Lepczyk CA, et al. A global analysis of the impacts of urbanization on bird and plant diversity reveals key anthropogenic drivers. Proc R Soc B. 2014;281:20133330.

Canário F, Leitão AH, Tomé R. Predation attempts by Short-eared and Longeared Owls on migrating songbirds attracted to artificial lights. J Raptor Res. 2012;46:232-4.

Chace JF, Walsh JJ. Urban effects on native avifauna: a review. Landsc Urban Plan. 2006;74:46-69.

Clarke JA. Moonlight's influence on predator/prey interactions between Shorteared Owls (Asio tlammeus) and deermice (Peromyscus maniculatus). Behav Ecol Sociobiol. 1983;13:205-9.

Crawley MJ. The R Book. Chichester: Wiley; 2012.

Da Silva A, Valcu M, Kempenaers B. Light pollution alters the phenology of dawn and dusk singing in common European songbirds. P Roy Soc B. 2015;370:20140126.

Debrot AO. Nocturnal foraging by artificial light in three Caribbean bird species. J Caribb Ornithol. 2014;27:40-1.

Dice LR. Minimum intensities of illumination under which owls can find dead prey by sight. Amer Naturalist. 1945;79:385-416.

Dominoni DM, Greif S, Nemeth E, Brumm H. Airport noise predicts song timing of European birds. Ecol Evol. 2016;6:6151-9.

Dykstra C, Simon M, Daniel F, Hays J. Habitats of suburban barred Owls (Strix varia) and red-shouldered hawks (Buteo lineatus) in Southwestern Ohio. J Raptor Res. 2012;46:190-200.

Enríquez PL. Los búhos neotropicales: Diversidad y conservación. México: El Colegio de la Frontera Sur; 2015.

Falfán I, MacGregor-Fors I. Woody neotropical streetscapes: a case study of tree and shrub species richness and composition in Xalapa. Madera bosques. 2016:22:95-110.

Falfán I, Muñoz-Robles CA, Bonilla-Moheno M, MacGregor-Fors I. Can you really see 'green'? Assessing physical and self-reported measurements of urban greenery. Urban For Urban Gree. 2018;36:13-21.

Fischer JD, Schneider SC, Ahlers AA, Miller JR. Categorizing wildlife responses to urbanization and conservation implications of terminology. Conserv Biol. 2015;29:1246-8.

Francis CD, Ortega CP, Cruz A. Noise pollution changes avian communities and species interactions. Curr Biol. 2009;19:1415-9.

Fröhlich A, Ciach M. Noise shapes the distribution pattern of an acoustic predator. Curr Zool. 2017;64:575-83.

Fröhlich A, Ciach M. Noise pollution and decreased size of wooded areas reduces the probability of occurrence of Tawny Owl Strix aluco. Ibis. 2018:160:634-46. 
Fröhlich A, Ciach M. Nocturnal noise and habitat homogeneity limit species richness of owls in an urban environment. Environ Sci Pollut R. 2019:26:1-8

Fuller RA, Warren PH, Gaston KJ. Daytime noise predicts nocturnal singing in urban robins. Biol Lett. 2007;3:368-70.

Galeotti P. Territorial behaviour and habitat selection in an urban population of the tawny owl Strix aluco L. Boll Zool. 1990;57:59-66.

Gaston KJ, Bennie J. Demographic effects of artificial nighttime lighting on animal populations. Environ Rev. 2014;22:323-30.

Gaston KJ, Bennie J, Davies TW, Hopkins J. The ecological impacts of nighttime light pollution: a mechanistic appraisal. Biol Rev. 2013;88:912-27.

Gerhardt RP, Gerhardt DM, Flatten CJ, González NB. The food habits of sympatric Ciccaba Owls in Northern Guatemala. J Field Ornithol. 1994;65:258-64.

González-Oreja JA. Relationships of area and noise with the distribution and abundance of songbirds in urban greenspaces. Landsc Urban Plan. 2017; 158:177-84

Gorenzel WP, Salmon TP. Characteristics of American Crow urban roosts in California. J Wildl Manag. 1995;59:638-45.

Grimm NB, Faeth SH, Golubiewski NE, Redman CL, Wu J, Bai X, et al. Global change and the ecology of cities. Science. 2008;319:756-60.

Gryz J, Krauze-Gryz D. Changes in the tawny owl Strix aluco diet along an urbanisation gradient. Biologia. 2019;74:279-85.

Hardouin LA, Robert D, Bretagnolle V. A dusk chorus effect in a nocturnal bird: support for mate and rival assessment functions. Behav Ecol Sociobiol. 2008;62:1909.

Himsworth CG, Jardine CM, Parsons KL, Feng AYT, Patrick DM. The characteristics of wild rat (Rattus spp.) populations from an inner-city neighborhood with a focus on factors critical to the understanding of rat-associated zoonoses. PLoS ONE. 2014;9:e91654.

Hindmarch S, Elliott JE. A specialist in the city: the diet of barn owls along a rural to urban gradient. Urban Ecosyst. 2015;18:477-88.

Hölker F, Wolter C, Perkin EK, Tockner K. Light pollution as a biodiversity threat. Trends Ecol Evol. 2010;25:681-2.

Holt DW, Berkley R, Deppe C, Enríquez-Rocha P, Petersen JL, Rangel-Salazar JL, et al. Mottled Owl (Ciccaba virgata). In: del Hoyo J, Elliott A, Sargatal J, Christie DA, de Juana E, editors. Handbook of the Birds of the World Alive. Barcelona: Lynx Edicions; 2019.

Howell S, Webb S. A guide to the birds of Mexico and northern Central America. Oxford: Oxford University Press; 1995.

INEGI. Prontuario de la información geográfica municipal de los Estados Unidos Mexicanos. Xalapa, Veracruz de Ignacio de la Llave. Clave geoestadística. 2009:30087.

Isaac B, White J, lerodiaconou D, Cooke R. Response of a cryptic apex predator to a complete urban to forest gradient. Wildlife Res. 2013;40:427-36.

Isaksson C, Rodewald AD, Gil D. Behavioral and ecological consequences of urban life in birds. Front Ecol Evol. 2018;6:50

Kettel EF, Gentle LK, Quinn JL, Yarnell RW. The breeding performance of raptors in urban landscapes: a review and meta-analysis. J Ornithol. 2018;159:1-18.

Knight E, Hannah K, Foley G, Scott C, Brigham R, Bayne E. Recommendations for acoustic recognizer performance assessment with application to five common automated signal recognition programs. Avian Conserv Ecol. 2017;12:14.

Kotler BP, Brown JS, Hasson O. Factors affecting gerbil foraging behavior and rates of owl predation. Ecology. 1991;72:2249-60.

Liu Z, He C, Zhou Y, Wu J. How much of the world's land has been urbanized, really? A hierarchical framework for avoiding confusion. Landsc Ecol. 2014;29:763-71

Lloyd H. Population densities of some nocturnal raptor species (Strigidae) in southeastern Peru. J Field Ornithol. 2013;74:376-80.

Longcore T, Rich C. Ecological light pollution. Front Ecol Environ. 2004;2:191-8.

Lövy M, Riegert J. Home range and land use of urban Long-eared Owls. Condor. 2013;115:551-7.

Luther D, Gentry K. Sources of background noise and their influence on vertebrate acoustic communication. Behaviour. 2013:150:1045-68.

Manzanares Mena L, Macías Garcia C. Songbird community structure changes with noise in an urban reserve. J Urban Ecol. 2018:4:1-8.

Marín-Gómez OH, MacGregor-Fors I. How early do birds start chirping? Dawn chorus onset and peak times in a Neotropical city. Ardeola. 2019:66:327-41.
Marín-Gómez OH, Toro Y, López-García MM, Garzón-Zuluaga Jl, SantaAristizabal DM. First records of the Spectacled Owl (Pulsatrix perspicillata) in urban areas, with notes on reproduction. North-West J Zool. 2017;13:368-71.

Marín-Gómez OH, Santiago-Alarcon D, Dátillo W, MacGregor-Fors I. Where has the city choir gone? Loss of the temporal structure of bird dawn choruses in urban areas. Landsc Urban Plan. 2020:194:103665.

Mason JT, McClure CJW, Barber JR. Anthropogenic noise impairs owl hunting behavior. Biol Conserv. 2016:199:29-32.

Maxwell SL, Fuller RA, Brooks TM, Watson JEM. Biodiversity: the ravages of guns, nets and bulldozers. Nature. 2016;536:143-5.

Menq W, Anjos L. Habitat selection by owls in a seasonal semi-deciduous forest in southern Brazil. Braz J Biol. 2015;75:143-9.

Merchant ND, Fristrup KM, Johnson MP, Tyack PL, Witt MJ, Blondel P, et al. Measuring acoustic habitats. Methods Ecol Evol. 2015;6:257-65.

Mori E, Bertolino S. Feeding ecology of long-eared owls in winter: an urban perspective. Bird Study. 2015;62:257-61.

Mori E, Menchetti M, Ferretti F. Seasonal and environmental influences on the calling behaviour of Eurasian Scops Owls. Bird Study. 2014;61:277-81.

Odom KJ, Mennill DJ. Vocal duets in a nonpasserine: an examination of territory defence and neighbour-stranger discrimination in a neighbourhood of barred owls. Behaviour. 2010;147:619-39.

Patón D, Romero F, Cuenca J, Escudero JC. Tolerance to noise in 91 bird species from 27 urban gardens of Iberian Peninsula. Landsc Urban Plan. 2012;104:1-8.

Penteriani $\vee$, Delgado M. The dusk chorus from an owl perspective: eagle owls vocalize when their white throat badge contrasts most. PLOS ONE. 2009; $4:$ :e4960

Penteriani V, Delgado MD, Stigliano M, Campioni L, Sánchez M. Owl dusk chorus is related to the quality of individuals and nest-sites. Ibis. 2014:156:892-5.

Poppleton M. Urban raptors: owl and hawk adaptation to urban centers. JUST. 2016:4:49-60.

Priyadarshani N, Marsland S, Castro I. Automated birdsong recognition in complex acoustic environments: a review. J Avian Biol. 2018;49:e01447.

R Core Team. R: A language and environment for statistical computing [Internet]. Vienna, Austria: R Foundation for Statistical Computing; 2018. http:// www.R-project.org/.

Ralph CJ, Geupel GR, Pyle P, Martin TE, DeSante DF. Handbook of field methods for monitoring landbirds. Albany: U.S.D.A., Forest Service, Pacific Southwest Research Station. Gen. Tech. Rep. PSW-GTR-144; 1996.

Ranazzi L, Manganaro A, Ranazzi R, Salvati L. Woodland cover and Tawny Owl Strix aluco density in a Mediterranean urban area. Biota. 2000;1:27-34.

Rebolo-Ifrán N, Tella JL, Carrete M. Urban conservation hotspots: predation release allows the grassland-specialist burrowing owl to perform better in the city. Sci Rep. 2017;7:3527.

Restrepo-Cardona JS, Betancur López A, Cano Castaño N. Abundancia y nuevos registros de búhos simpátricos en Manizales y Villamaría (Caldas, Colombia). Bol Cient Mus His Nat. 2015;19:220-9.

Rivera-Rivera E, Enríquez PL, Flamenco-Sandoval A, Rangel-Salazar JL. Ocupación y abundancia de aves rapaces nocturnas (Strigidae) en la Reserva de la Biosfera Selva El Ocote, Chiapas. México. Rev Mex Biodiv. 2012;83:742-52.

Rullman S, Marzluff JM. Raptor presence along an urban-wildland gradient: influences of prey abundance and land cover. J Raptor Res. 2014;48:257-72.

Santiago-Alarcon D, Delgado VC. Warning! Urban threats for birds in Latin America. In: MacGregor-Fors I, Escobar-lbáñez JF, editors. Avian ecology in Latin American Cityscapes. Cham: Springer; 2017. p. 125-42.

Saufi S, Ravindran S, Hamid NH, Abidin CMRZ, Ahmad H, Ahmad AH, et al. Diet composition of introduced Barn Owls (Tyto alba javanica) in urban area in comparison with agriculture settings. J Urban Ecol. 2020;6:1-8.

Scobie CA, Bayne EM, Wellicome TI. Influence of human footprint and sensory disturbances on night-time space use of an owl. Endanger Species Res. 2016;31:75-87.

Senzaki M, Yamaura Y, Francis CD, Nakamura F. Traffic noise reduces foraging efficiency in wild owls. Sci Rep. 2016;6:30602.

Serieys LE, Bishop J, Okes N, Broadfield J, Winterton DJ, Poppenga RH, et al. Widespread anticoagulant poison exposure in predators in a rapidly growing South African city. Sci Total Environ. 2019;666:581-90. 
Seto KC, Fragkias M, Güneralp B, Reilly MK. A Meta-analysis of global urban land expansion. PLoS ONE. 2011;6:e23777.

Ševčík R, Riegert J, Šindelár J, Zárybnická M. Vocal activity of the Central European Boreal Owl population in relation to varying environmental conditions. Ornis Fennica. 2019;96:1-12.

Shonfield J, Bayne EM. The effect of industrial noise on owl occupancy in the boreal forest at multiple spatial scales. Avian Conserv Ecol. 2017;12:13.

Shonfield J, Heemskerk S, Bayne EM. Utility of automated species recognition for acoustic monitoring of Owls. J Raptor Res. 2018:52:42-55.

Sierro J, Schloesing E, Pavón I, Gil D. European blackbirds exposed to aircraft noise advance their chorus, modify their song and spend more time singing. Front Ecol Evol. 2017;5:68.

Slabbekoorn H. Songs of the city: noise-dependent spectral plasticity in the acoustic phenotype of urban birds. Anim Behav. 2013;85:1089-99.

Sol D, Lapiedra O, González-Lagos C. Behavioural adjustments for a life in the city. Anim Behav. 2013;85:1101-12.
Vázquez-Pérez JR, Enríquez PL. Factores temporales y ambientales asociados a los llamados de los búhos en la Reserva Selva El Ocote, Chiapas, México. Hornero. 2016;31:83-8.

Weaving MJ, White JG, Isaac B, Cooke R. The distribution of three nocturnal bird species across a suburban-forest gradient. Emu. 2011;111:52-8.

Wildlife Acoustics. https://www.wildlifeacoustics.com/products/kaleidosco pe-pro/tutorial-videos. Accessed 20 May 2019.

Williams-Linera G. Vegetación de bordes de un bosque nublado en el Parque Ecológico Clavijero, Xalapa, Veracruz, México. Rev Biol Trop. 1993;41:443-53.

Zuur AF, Leno EN, Elphick CS. A protocol for data exploration to avoid common statistical problems. Methods Ecol Evol. 2010;1:3-14.
Ready to submit your research? Choose BMC and benefit from:

- fast, convenient online submission

- thorough peer review by experienced researchers in your field

- rapid publication on acceptance

- support for research data, including large and complex data types

- gold Open Access which fosters wider collaboration and increased citations

- maximum visibility for your research: over $100 \mathrm{M}$ website views per year

At BMC, research is always in progress.

Learn more biomedcentral.com/submissions 